\title{
Intelligent Control System Architecture for Phosphorus Production from Apatite-Nepheline Ore Waste
}

\author{
Maksim Dli ${ }^{1}$, Andrey Puchkov ${ }^{1, *(D)}$, Artem Vasiliev ${ }^{2}$, Elena Kirillova ${ }^{1}$, Yuri Selyavskiy ${ }^{3}$ and Nikolay Kulyasov $^{4}$ \\ 1 Department of Information Technology in Economics and Management, National Research University \\ “Moscow Power Engineering Institute" (Smolensk Branch), 214013 Smolensk, Russia; midli@mail.ru (M.D.); \\ kirillova.el.al@yandex.ru (E.K.) \\ 2 Rector, Moscow University for Industry and Finance "Synergy", 129090 Moscow, Russia; synergy@synergy.ru \\ 3 Department of Economics and Trade, Plekhanov Russian University of Economics (Smolensk Branch), \\ 214030 Smolensk, Russia; yurasel83@mail.ru \\ 4 Higher School of Tariff Regulation, Plekhanov Russian University of Economics, 117997 Moscow, Russia; \\ nkulyasov@gmail.com \\ * Correspondence: putchkov63@mail.ru
}

Citation: Dli, M.; Puchkov, A.; Vasiliev, A.; Kirillova, E.; Selyavskiy, Y.; Kulyasov, N. Intelligent Control System Architecture for Phosphorus Production from Apatite-Nepheline Ore Waste. Energies 2021, 14, 6469. https://doi.org/10.3390/ en14206469

Academic Editor: Eduard Petlenkov

Received: 31 July 2021

Accepted: 29 September 2021

Published: 9 October 2021

Publisher's Note: MDPI stays neutral with regard to jurisdictional claims in published maps and institutional affiliations.

Copyright: (C) 2021 by the authors. Licensee MDPI, Basel, Switzerland. This article is an open access article distributed under the terms and conditions of the Creative Commons Attribution (CC BY) license (https:// creativecommons.org/licenses/by/ $4.0 /)$.
Abstract: This paper proposes multilevel architecture for an intelligent control system for the complex chemical energy technological process of yellow phosphorus production from apatite-nepheline ore processing waste. The research revealed that, when controlling this process, one has to deal with large amounts of multiformat and polymodal information, and control goals differ at different levels not only in effectiveness criteria, but also in the structuredness of the level problems. On this basis, it is proposed that intelligent methods be used for the implementation of information processes and control goals at individual levels and the whole system. The artificial intelligence methods underlying the informational model of a control system offer solutions to problems of analyzing control processes at different hierarchy levels, namely the initial level of sensing devices, the levels of programmable logic controllers, dispatching of control and production processes, enterprise management and strategic planning. Besides, the intelligent control system architecture includes analytical and simulation models of processes occurring in the multistage procedure of ore waste processing by a plant consisting of a granulating machine, a conveyor-type multichambercalcining machine, and an ore thermal furnace. The architecture of information support for the control system comprises a knowledge-based inference block intended for implementing the self-refinement of neural network and simulation models. Fuzzy logic methods are proposed for constructing this block. The paper considers the deployment of control algorithms for a phosphorus production system using the Matlab software environment on the basis of a modern complex system development paradigm known as the model-oriented design concept.

Keywords: information model; intelligent control systems; waste processing

\section{Introduction}

The implementation of projects in the field of new flow sheets for the recycling of wastes from various industries is currently one of the ways of reducing the adverse effects of human industrial activity on the environment [1-3]. The importance of such processing increases notably when the amount of waste is large and when it is rich in chemical and mineralogical composition. This enables us to classify such wastes as technogenic deposits $[4,5]$.

Waste processing requires design and construction of advanced plants performing complex, multistage, and interrelated technological operations of processing various raw materials. A special contribution to performing these operations is made by their information support solving a complex of satellite control and optimization problems, including those aimed at increasing the energy and resource efficiency of processing and its environmental safety [6,7]. 
Large processing plants, such as mining-and-processing integrated works, were designed and constructed tens of years ago, when less attention than now was paid to the tasks of reducing energy and resource consumption and decreasing the adverse effect on the environment. These tasks can be solved along two lines: (i) implementation of novel processes with entire re-equipment; (ii) optimization of existing technological concepts by implementing industrial waste recycling, upgrading information support, and improving control schemes. The former case requires considerable material and time consumption, and sometimes suspension of production. Therefore, in terms of minimization of material costs, the latter line can be a reasonable alternative as a short-term solution (before general modernization of production), which implies an integrated approach due to complementing existing procedures by waste recycling, as well as optimization of control schemes and information support of the process by means of advanced digital solutions.

The apatite-nepheline ore waste processing plant discussed in this paper is a complex chemical and energy technology system (CETS). It comprises three successively arranged process units: a granulator, a conveyor type multi-chamber calcining machine, (CTMCM), and an ore thermal furnace (OTF) [8]. The control of the CETS requires forming a complex hierarchic information support, which, besides the functions of collecting information from the gauging equipment and control, would perform intelligent monitoring of the health of the CETS, predictive analysis, and optimization of energy and resource consumption.

The aim of this study is to develop intelligent control system architecture for a complex CETS of recycling wastes from apatite-nepheline ore processing for the production of yellow phosphorus. The research tasks were to analyze the structure of the technological chain of ore waste processing, the proposed mathematical models of separate units (including their use for operation mode optimization), and experience in using advanced information systems for supporting technological processes, as well as to develop an information model of the control system for the CETS of recycling apatite-nepheline ore processing waste.

The paper describes the composition and functions of data conversion and processing elements in the CETS control loop, which determine the proposed structure of the information model. It also presents some aspects of the project on its implementation.

\section{The Potential of Phosphorus Extraction from Apatite-Nepheline Ore Waste}

Intensive human industrial activity produces large amounts of phosphorus-containing waste (P-waste). When moving into the environment, it causes eutrophication and littering of large territories near mining-and-processing integrated works, adversely affecting human health. Until recently, plant cultivation was the main source of P-waste; however, P-waste from phosphate mining and phosphorus chemical production is currently showing the most rapid growth [9]. According to the data provided by the Mining Institute of the Kola Science Center of the Russian Academy of Sciences, only for three miningand-processing complexes (Apatit JSC (Kirovsk, Russia), Olkon JSC (Olenegorsk, Russia), and Kovdor GOK JSC (Kovdor, Russia)), the amounts of technogenic raw materials accumulated in the Murmansk region of Russia increased from $2500 \mathrm{Mt}$ in 1985 to $6764 \mathrm{Mt}$ in 2015.

Phosphorus-containing technogenic wastes from the mining-and-processing complexes situated in the Murmansk region differ in the mineralogical and chemical compositions of the substrates; however, all of them are mainly fine siliceous-carbonate raw materials with complex phosphate oolites. The increasing consumption of phosphates generates a threat of phosphorus resource depletion; therefore, apatite-nepheline ore waste recycling is of crucial importance in solving these problems. The heterogeneity of the characteristics of technogenic waste from raw materials to be dressed necessitates the application of new approaches to the construction of CETS for phosphorus production from apatite-nepheline ore waste with regard to the variability of the characteristics of batches from different dumps.

Analysis of the potential of extracting phosphorus from apatite-nepheline ore waste testifies that, e.g., the dumps of the Apatit JSC $\left(\mathrm{P}_{2} \mathrm{O}_{5}\right.$ of about 0.3 to $\left.0.5 \%\right)$ can yield an 
apatite product with a phosphorus content of 25 to $30 \%$ after processing. This phosphorus concentration is fairly sufficient for agricultural needs. The product, in turn, can be forwarded for further dressing, which results in the additional output of the finished product.

This study of the composition of the dumps shows that they consist mainly of a fine raw material, which determines the expediency of its preliminary palletization followed by heat treatment. This method, implemented in the CETS discussed in this paper, enables one not only to make phosphorus-containing products, but also to transport phosphorite pellets to be subsequently processed within logistically efficient P-waste utilization systems.

\section{Materials and Methods}

The procedure of control of the complex CETS for producing phosphorus from apatitenepheline ore waste is characterized by multilevel architecture; each level engaged in solving the general problem, i.e., ensuring maximum phosphorus production volume, and takes into account the specificity of the problems of each level, starting from actuators and ending with the level of decision making by enterprise management.

The hierarchical structure of the information model for the CETS control system can be considered in terms of both the executed functions and the facilities used to provide information interaction:

- the initial level presenting information processes providing collection and preprocessing of signals from sensors, including intelligent ones, and sensing devices (normalization, standardization, etc.) mounted on different units and in different zones of the process equipment;

- the level of programmable logic controllers connected by a fieldbus for effective and coordinated information exchange, including interlevel one, and elaboration of controlling actions following the embedded algorithm;

- the level of control dispatching, represented by automated jobs and SCADA software packages (Supervisory Control and Data Acquisition) allowing real-time operation of the systems for collecting and processing of data with the object of monitoring or control;

- the level of controlling production processes at which specialized applied software of the MES class (manufacturing execution system) is used to solve problems of synchronization, analysis, and optimization of product manufacturing [10,11];

- the level of enterprise management at which resource (production, HR, finance, logistics) management is automated by means of ERP systems (Enterprise Resource Planning) [12,13]; - the level of strategic planning when various OLAP systems (online analytical processing) are used to aggregate and analyze information from large amounts of data structured according to the multivariate principle $[14,15]$.

It is expedient to improve the information support of the CETS on the basis of advanced technologies towards digital integration and intellectualization of data processing algorithms at all levels $[15,16]$. The intelligent control system architecture for the CETS is shown in Figure 1, where the blocks highlighted by a thick frame represent the proposed generalized information model of the conversion and processing of the data contained in the control loop. The information flows shown in Figure 1 are marked by thick arrows, whereas the thin arrows show actions at the level of physical processes and signals.

The formation of the goal of management at each level of the above information model hierarchy is governed by local tasks; however, each higher level is based on the results of control obtained at the lower level. In view of the diversity of these goals, and the complexity of goal achievement, local software is developed for each level, which provides integration with the neighboring levels for information interaction.

The Goal Achievement Program and Control Algorithm blocks are two stages of forming controlling actions on actuators, i.e., the program determines the change of information support levels, at each of which a specialized algorithm for achieving the goal of this level is applied. 


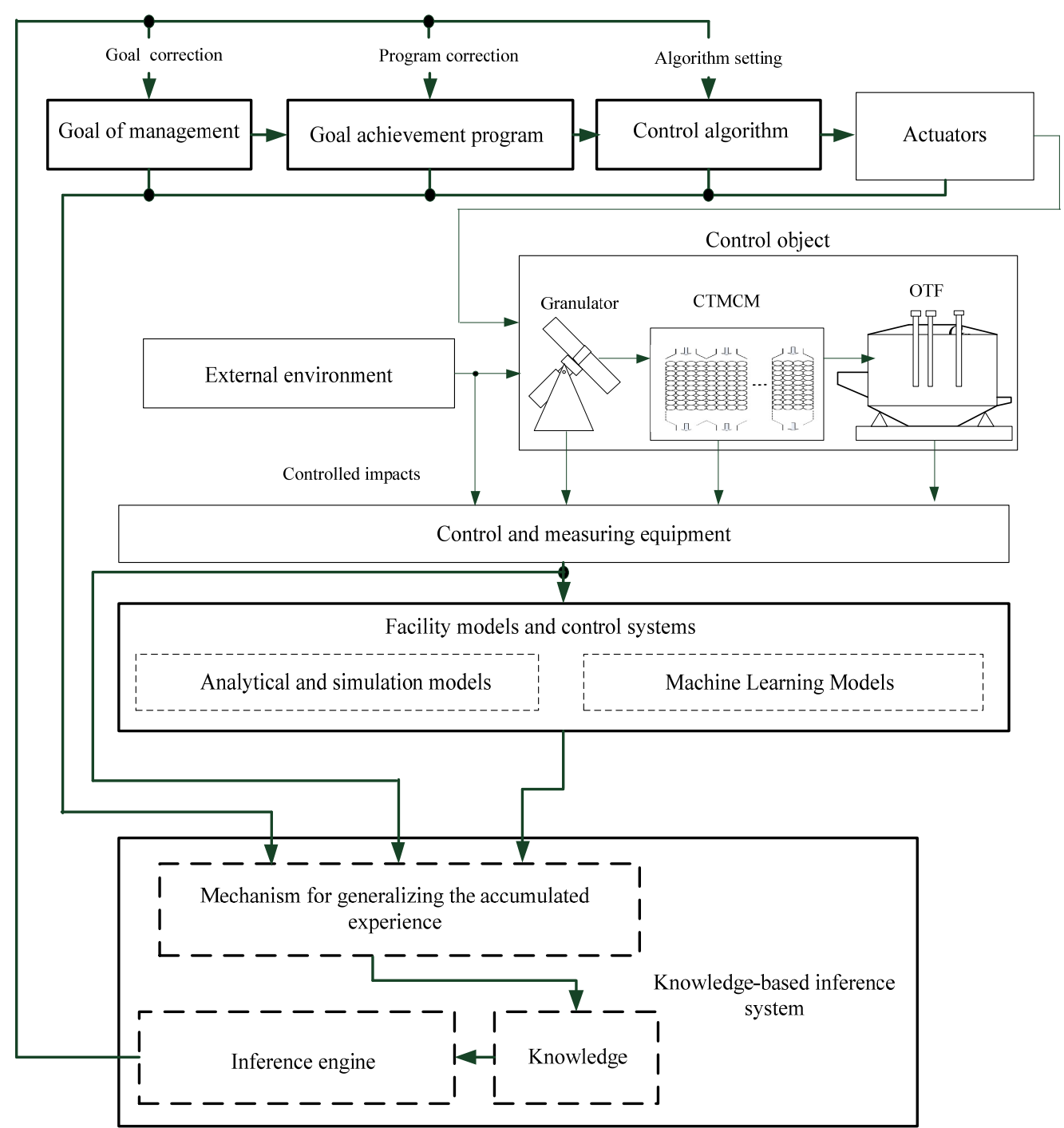

Figure 1. The structure of the CETS intelligent control system.

Actuators mean not only engineering devices of lower levels, but also resources implementing control at the level of enterprise management and strategic planning.

The control structure presented in Figure 1 possesses the properties of self-learning and adaptation to the changing external environment conditions and control goals. For this purpose, blocks of models and a knowledge-based inference system are included in the information model, which analyze the results and generalize the control experience, using it for goal, program, and control algorithm correction.

The complexity of the CETS leads to the fact that the analytical models of individual CETS units are developed on different conceptual bases, and they do not always agree in input-output in terms of both signal nomenclature and representation form $[9,17]$. Besides, the complexity of describing the physical, thermal-hydraulic, and physical-chemical processes in the CETS, and the necessity to take into account the effect of random factors, including the external environment, justifies the application of simulation models, the results of experiments with them being also used in the knowledge-based inference system.

In the presented architecture of the CETS control system, machine learning is used for predictive analysis, particularly for predicting the health of the individual CETS units and evaluating the remaining useful life (RUL) of the equipment $[18,19]$. In view of the polymodality of the information on the CETS, ensemble decisions based on various machine learning methods are used to analyze it, namely deep convolutional and recurrent neural networks, decision trees, statistical procedures of data processing, which are chosen 
on the basis of the pre-assessment of incoming information in terms of its pragmatic value for simulation goals.

The knowledge-based inference system can use various knowledge representation models; however, a fuzzy logic paradigm was chosen in this case, where the requirements on the determination of parameter values are lower and processing of linguistic variables is allowed, this being important in the application of expert judgements. These circumstances favor the widespread use of fuzzy systems when controlling various objects, among other things, in terms of the minimum energy consumption criterion $[20,21]$.

The Control Algorithm block involve stuning of control algorithms, i.e., various procedures at different levels, which are governed by the controller structure and the control goals. The level of the programmable logic controllers implements algorithms for controlling the actuators directly acting on the input material and energy flows of the control object. At this level, algorithmically simple proportional integral derivative (PID) controllers and their modifications successfully manage control tasks; however, it is a separate task to tune them. To do this, numerous methods have been developed [22], including those using fuzzy logics, machine learning, and genetic algorithms [23-25]. PID-controllers are often embedded in real-time systems where control algorithm parameters change slowly or demonstrate vagueness, thus making prediction very difficult and lagged [26]. These controllers are used not only to maintain the absolute values of the parameters, but also to adjust their interrelations, e.g., in the task of ensuring the specified yield of a substance in a technological process. Practical use of controllers encounters a number of difficulties caused by the necessity to determine the characteristics of a control object, as well as control system nonlinearity and nonstationary state; however, the application of machine learning methods to the tuning of PID controllers enables these difficulties to be successfully overcome [27].

In the CETS under study, the proportion of yellow phosphorus in the gas fraction evacuated from the OTF reactor zone is important. However, in one form or another, the parametric controller tuning methods require the calculation of the optimization criterion for neural network training, base formation or population selection, and this leads to additional time and computational resource consumption.

The presence of three units in the CETS, and several quantities to be controlled in each of them, necessitates using numerous controllers, this being shown in Figure 2, where PID $_{\mathrm{G}}, \mathrm{PID}_{\mathrm{CTMCM}}$, and PID $\mathrm{OTF}$ are PID controllers of the corresponding units, N, M, and K are the number of control channels in these units. Such controllers are currently created on the basis of programmable logic controllers as specialized hardware modules, or by program methods, with the use of specialized libraries [28,29].

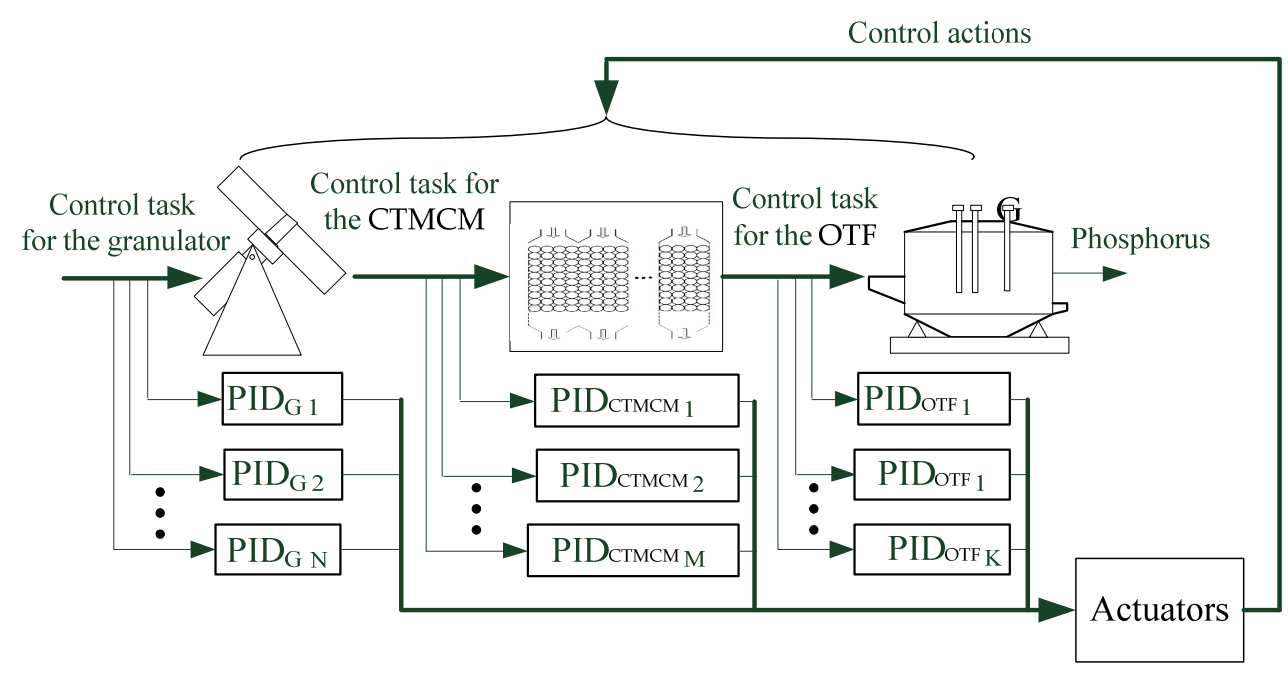

Figure 2. The structure of the CETS control system at the level of controllers. 
The arrangement of controllers shown in Figure 2 results in the fact that their tunings are optimized independently, without consideration of the optimality of the whole CETS in terms of this or that quality criterion. In order to overcome these difficulties, it is proposed that a neural network embedded in the control loop be applied. Its fragment for one control channel is shown in Figure 3. The blue color highlights the blocks belonging to the modified structure of an artificial neuron with the function of activation $(\mathrm{q})$, which is termed the PID neuron. Displacement in the PID neuron structure is not used since there are only three parameters in the PID control law.

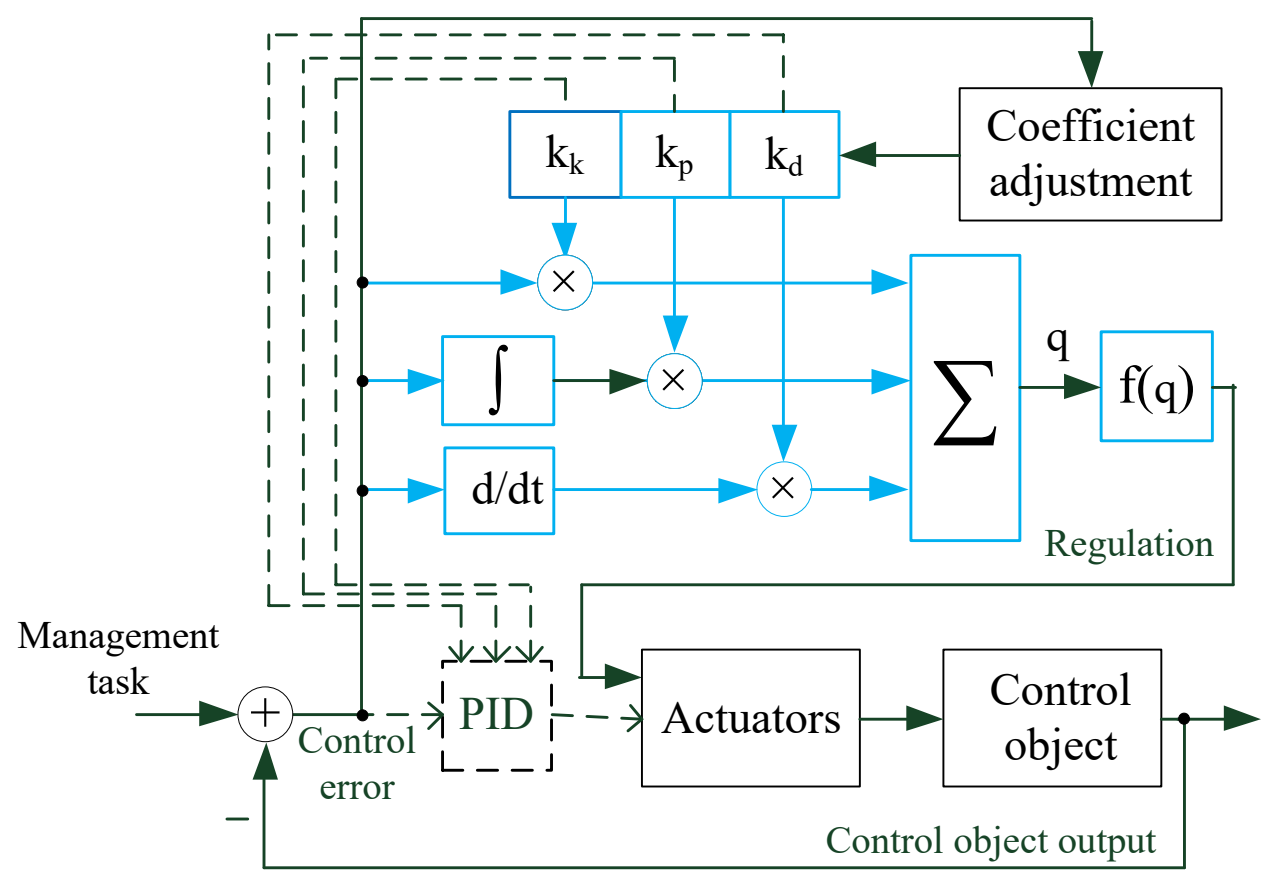

Figure 3. Control channel architecture with an artificial PID neuron.

The proposed PID neuron architecture is based on its analogy with the PID controller, i.e., both are parametric models that are adaptable to the changing conditions of the external environment. The weights of the PID neuron synapse are put in correspondence to the proportional $\left(\mathrm{k}_{\mathrm{k}}\right)$, integral $\left(\mathrm{k}_{\mathrm{p}}\right)$, and differential $\left(\mathrm{k}_{\mathrm{d}}\right)$ components of the control law.

In the architecture presented in Figure 3, the PID controller is tuned in two stages:

- primary optimization of the controller parameters $\mathrm{k}_{\mathrm{k}}, \mathrm{k}_{\mathrm{p}}$, and $\mathrm{k}_{\mathrm{d}}$ with the application of standard procedures;

- controller parameter refinement during operation due to PID neuron training on the basis of the incoming data with the subsequent transmission of the found synapse weights $\mathrm{k}_{\mathrm{k}}, \mathrm{k}_{\mathrm{p}}$, and $\mathrm{k}_{\mathrm{d}}$ into the controller.

At the first stage, the controllers can be tuned with the application of the analytical and simulation models of the control object and controlled external actions. Dynamic models be used here, whose parameters are determined by acceleration characteristics [30], as well as models based on neural networks [31,32].

At the second stage of tuning, model construction is unnecessary when the PID neurons are integrated in the loop of information conversion in the control system. In this case, the controller tuning parameters are adapted in real time with the use of constantly renewed data.

A control error taken as a basis for coefficient adjustment acts as the neuron network (PID neuron) training error.

The collection of PID neurons of individual control channels for the whole CETS represents an artificial neural network. Its architecture is shown in Figure 4. 


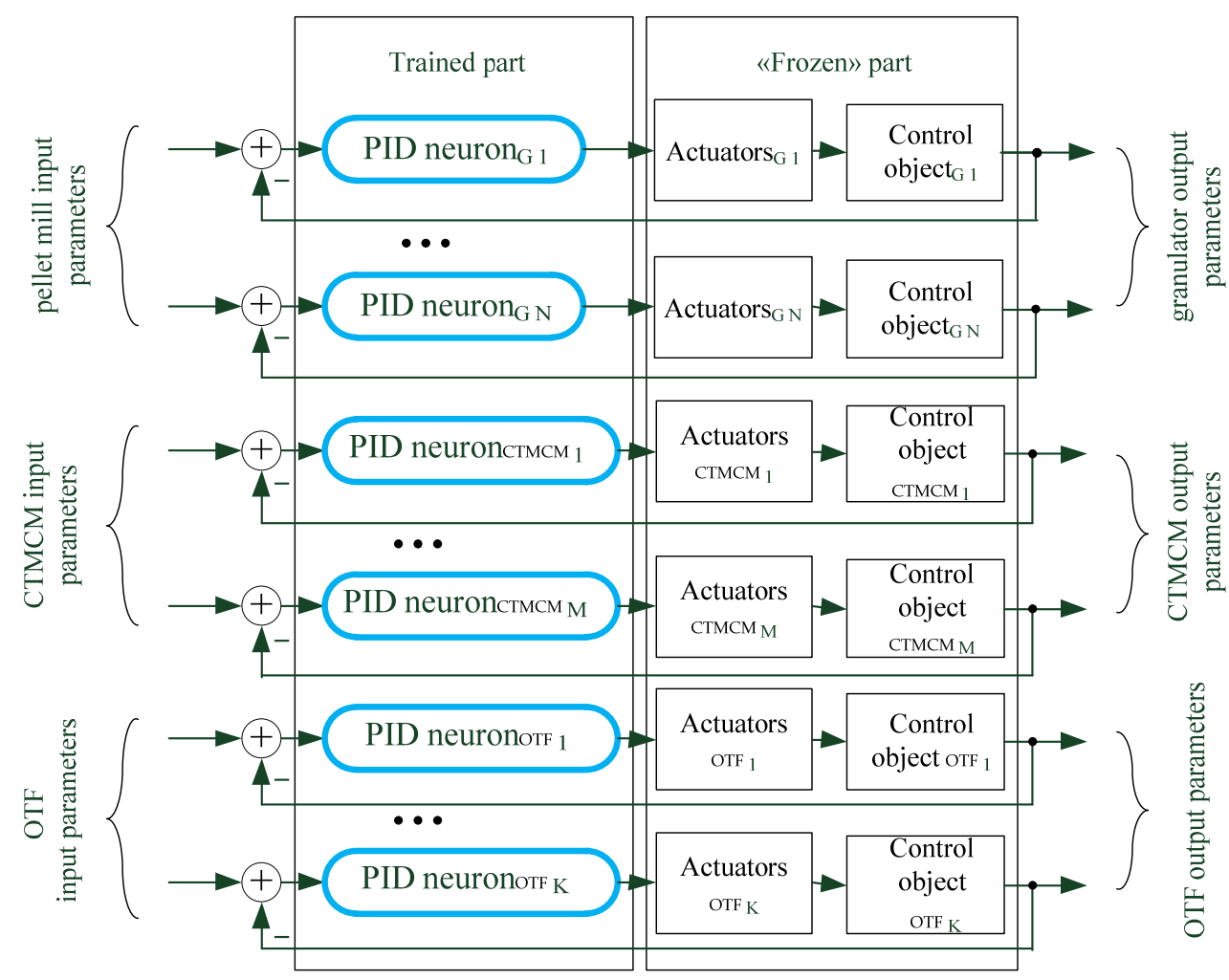

Figure 4. Architecture of the neural network for controller tuning.

The blue color in Figure 4 indicates neurons belonging to the part trained during tuning. Actuator and control object models are excluded from the training process and grouped into a "frozen" part. This term is used in the neural network theory to denote the part excluded from training.

\section{Results}

In order to develop the elements of the intelligent control system for the CETS, we chose the Matlab software environment for scientific and technical calculations and simulation, which has a rich set of data analysis tools, including those for the application of fuzzy logics (Fuzzy Logic Toolbox), deep machine learning (Deep Learning Toolbox), dynamic system simulation and simulation modeling (Simulink). In the Deep Learning Toolbox there is a tool for creating a predicting controller using a neural-network-based model of a nonlinear object designed for predicting the future efficiency of the object in terms of some criterion. The controller then computes the control input optimizing the efficiency of the object within a specified future time span. In the implementation of the PID neuron, the PID controller tuning coefficients are extracted from the array of synapse weights, which in Matlab are implemented as the IW cell array of the dimensions $\mathrm{Nl} \times \mathrm{Ni}$, where $\mathrm{Nl}$ is the number of network layers (net.numLayers) and $\mathrm{Ni}$ is the number of network inputs (net.numInputs).

Taking into account the complexity of the CETS under study, we adduce the results of implementation of one architectural concept in the presented intelligent control system, namely a neural controller. A granulator having several input parameters is chosen for consideration: $G_{1}$ is the crude ore mass flow rate, $D$ is apatite-nepheline ore waste dispersion and $u$ is moisture mass fraction in the waste. The output parameters for the granulator are as follows: $G_{2}$ is green pellet mass flowrate, $r$ is raw granule radius, $f$ is granule moisture and $\varepsilon$ is pellet porosity. The illustrative example is restricted to the consideration of one control channel $\mathrm{G}_{2}\left(\mathrm{G}_{1}\right)$.

In the adjustment loop, process parameters vary with time continuously and the control device is rated as a discrete element implemented by programable logic controllers; 
therefore, the block diagram of such a loop is discrete and continuous. For simulation, the block diagram in systems of this form must be converted into either a continuous form or a discrete one. Transformation into an equivalent discrete system is based on the process of obtaining a discrete signal with pulse-amplitude modulation from a continuous signal by time quantization and rectangular pulse formation. The quantization is performed by an ideal pulse element, and the pulse is formed by a zero-order predictor. An equivalent z-transfer function is written for the tandem-connected clamp and object (the reduced continuous part). It can be calculated by different methods. This study uses the Matlab function c2d (Woc, T), where Woc is the continuous transfer function of the object and T is the quantization period. The quantization period is selected as the greatest common deviser of all the object time constants, including the lag time constant.

To tune PID controllers, it is necessary to know the model of the object controlled through the specified channel. The continuous transfer function for this channel was obtained by approximation of the acceleration characteristic [30] and has the form

$$
W_{G G(s)}=\frac{0.83 e^{-25 s}}{52 s+1},
$$

where $\mathrm{s}$ is the Laplace complex variable.

The time constant $\tau=25 \mathrm{~s}$, and the object constant $\mathrm{T}_{\mathrm{O}}=52 \mathrm{~s}$. The delay $e^{-25 \mathrm{~s}}$ is taken into account in $\mathrm{z}$-transformation by the multiplier $\mathrm{z}^{\mathrm{v}}$, where $\mathrm{v}=\tau / \mathrm{T}$. Assuming that $\mathrm{T}=25 \mathrm{~s}$, we have $\mathrm{v}=1$. The discrete transfer function was determined in Matlab by means of the following instruction code: sys $1=\mathrm{tf}([0.83]$, [52 1], 'inputdelay', 25); sys2 = c2d(sys1,25). This results in the following transfer function of the reduced continuous part for Equation (1):

$$
W_{G G_{-} r c p(z)}=\frac{0.3168}{z(z-0.6183)},
$$

where $z$ is a one sampling step delay operator.

The controller type is selected with allowance for the lag time constant to object time constant ratio, 25/52 $=0.48$; this falls in the range [0.2; 0.7], for which the use of a Pic ontroller is expedient. As a result, the transfer function of an open-loop system with a PI controller and a reduced continuous part becomes

$$
W_{o g(z)}=\frac{k_{r}\left(\left(1+\frac{T}{T_{i}}\right) z-1\right)}{z-1} \frac{0.3168}{z(z-0.6183)},
$$

where $k_{r}$ and $T_{i}$ are the transfer coefficient and the controller time constant.

The optimum controller parameters [33] were calculated from the conditions for ensuring overcorrection not worse than $25 \%$, and the control time $t_{c}<120-160 \mathrm{~s}$. The following values were obtained: $k_{r}=0.95, T_{i}=33 \mathrm{~s}$.

The model implemented in Simulink is shown in Figure 5. The control task is entered through the control input terminal and fed to the two branches of the model: one branchiomeres PI controller with calculated parameters, and the other contains a PID neuron implemented as a Matlab function.

In order to simulate changes in the object parameters, var_k block is introduced in the model as a Matlab function. The PI controller tunings in branchIremain unchanged, and correspond to the transfer function represented by Equation (2). The PID neuron synapse weights change, and this provides control adaptation to the variation of the var_k block coefficient. Centered Measurement Noise is introduced in the model in order to simulate instrumentation errors. 


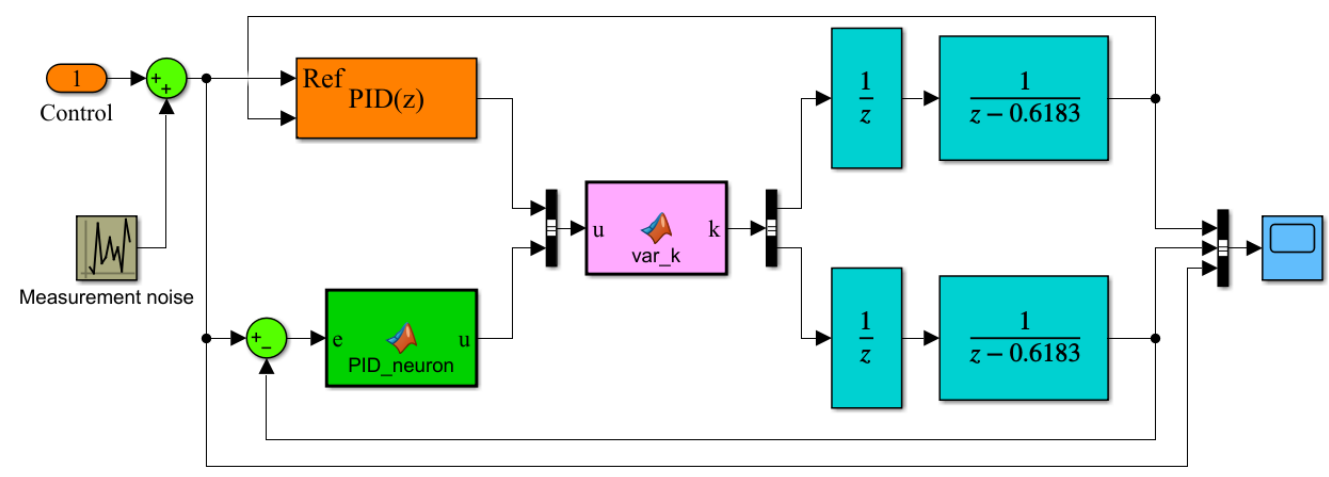

Figure 5. The control channel model in the Simulink environment.

During the experiment, the variation of the var_k coefficient was specified on several model time intervals, according to Table 1, at a constant control task value (the control task value remained unchanged within the entire simulation time).

Table 1. Variation of the var_k coefficient on time intervals.

\begin{tabular}{ccc}
\hline No. & Time Interval, $\mathbf{s}$ & var_k \\
\hline 1 & $0-2000$ & 0.3168 \\
\hline 2 & $2001-4000$ & 0.38 \\
\hline 3 & $4001-6000$ & 0.15 \\
\hline 4 & $6001-8000$ & 0.42 \\
\hline 5 & $8001-10,000$ & 0.45 \\
\hline
\end{tabular}

Figure 6 presents control system output diagram sat the variation of the var_k coefficient according to the data from Table 1. The blue color indicates the outputs of model branch I with a PI controller having fixed tunings. The red color highlights the out put of the model branch containing a PID neuron.

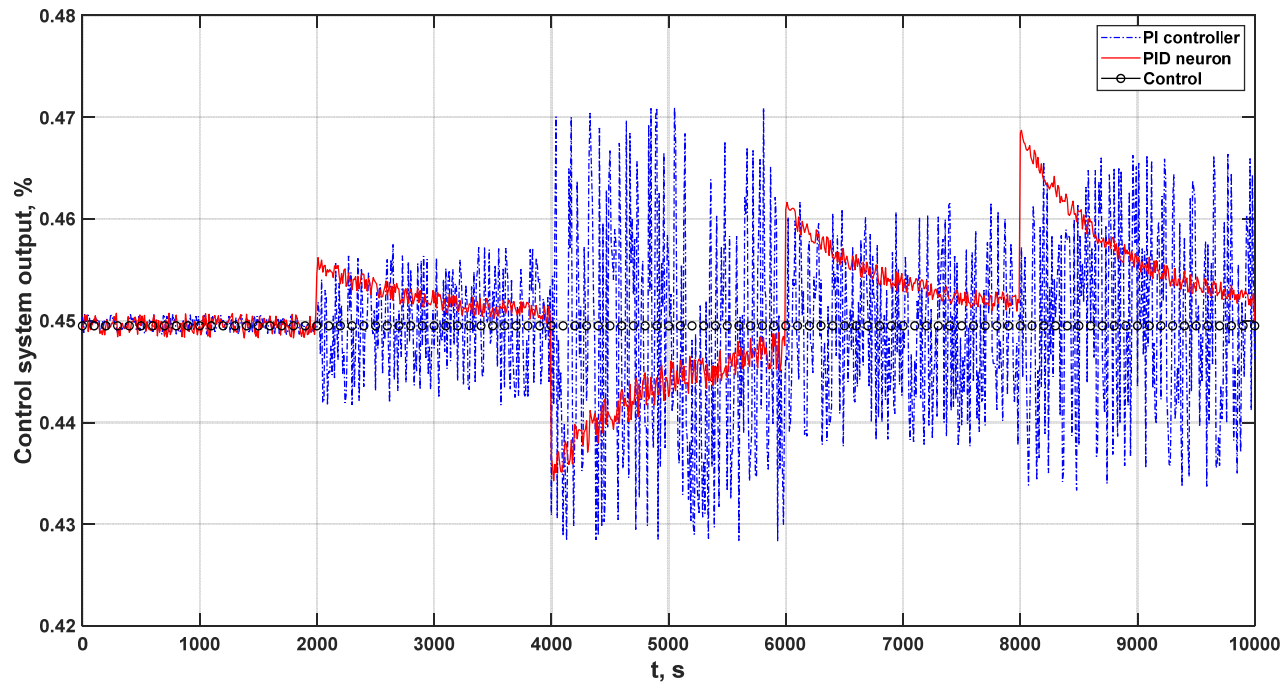

Figure 6. Simulation results.

The visual analysis of the diagrams suggests that, during PID neuron training, the system output gradually returns to the specified value, whereas the output of model branch Icontinues to fluctuate, this being caused by the absence of the adaptation of controller tuningsto the changes in the var_k parameter of the control object.

The HDL Coder tool is used to deploy the CETS control algorithms on embedded devices in Matlab. From it, Matlab functions and models in Simulink, and creates a code 
portable to the Verilog and VHDL hardware description language platforms. The thus obtained HDL code is used to program a field-programmable gate array (FPGA) or to prototype and design an application-specific integrated circuit (ASIC). Summarizing the foregoing, we can represent the sequence of the stages in developing the CETS control system by the scheme illustrated in Figure 7 .

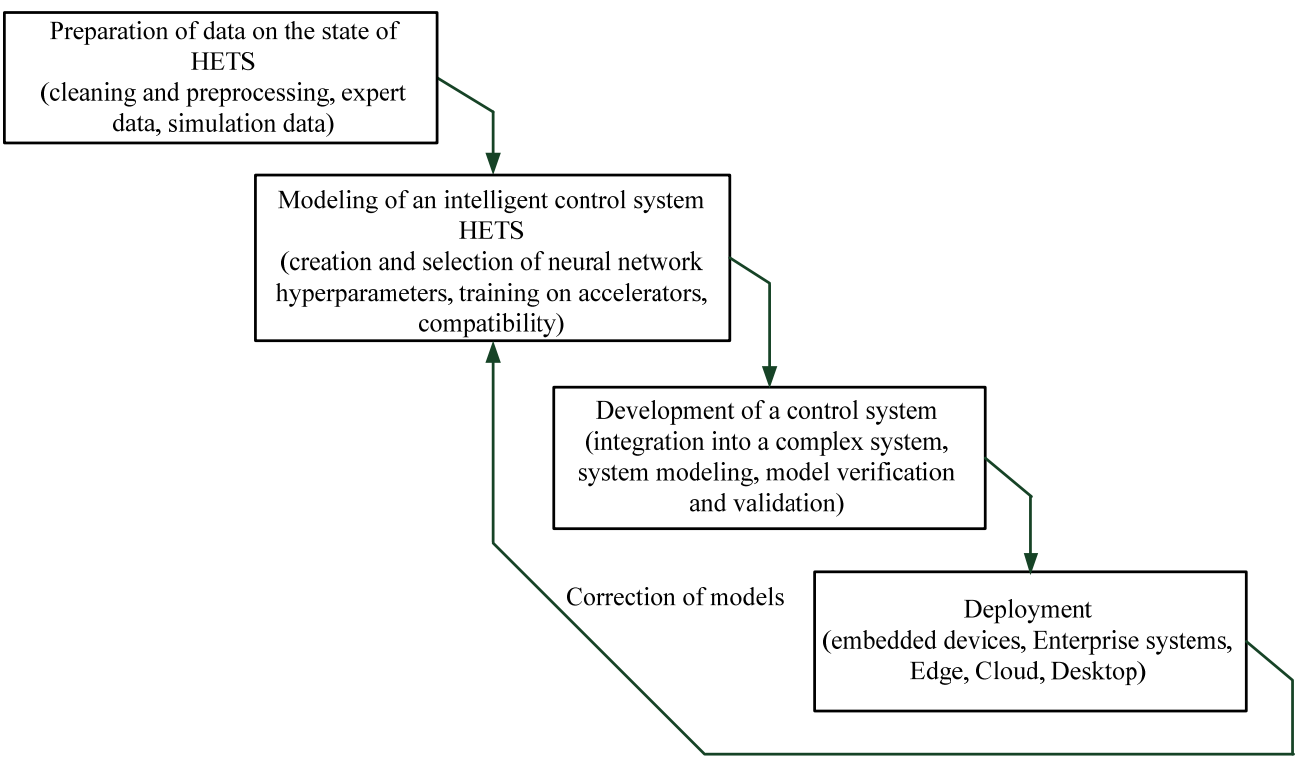

Figure 7. The sequence of stages in developing an intelligent control system for CETS.

For integration with neural network models created by means of other development environments, the ONNX interface with a neural network exchange system is used. It is an open standard format into which machine learning models are transformed from such platforms and frameworks as TensorFlow, PyTorch, SciKit-learn, keras, Chain, MXNET, and SparkML.

The presented MathWorks tools enable one to implement the concept of modeloriented design of the CETS control system, which is an advanced paradigm of developing complex systems. The application of this approach places the CETS model in the center of development, which undergoes evolution in the process of development, i.e., at first it is a high-level system model in which system components and their interrelations are described, yet still without a detailed elaboration of the components.

Specific requirements are bound to the components, according to which the latter are subsequently detailed, with a functional being added to them. This development process arrangement allows one to design multidomain systems and to study and optimize the work of whole systems, e.g., like the here-discussed CETS.

At the implementation stage, automated code generation tools are used and trade-off decisions are studied and optimized. The entire development process, from creation of requirements to implementation, is accompanied by continuous testing and verification. The application of a model-oriented approach has enabled errors to be revealed and eliminated at early stages of project evolution.

\section{Discussion}

The research yielded a multilevel architecture of an intelligent control system for a complex CETS producing phosphorus from environmentally hazardous apatite-nepheline waste accumulating in large volumes in the tailing ponds of mining-and-processing integrated works. The proposed information model determining the scientific novelty of the research is based on the application of artificial intelligence methods (machine learning, fuzzy logic) at various levels of control to solving problems of simulation, analysis, accumulation and generalization of experience for control goal achievement optimization. The 
concept of model-oriented prototyping and designing CETS elements enable to execution of the iterative process of revealing and eliminating errors at various stages of creating a control system, as well as achieving the highest possible consistency of developed model sand algorithms with control goals. The research results allow us to recommend it for use. The selection of Matlab as the implementation environment is debatable; however, its current versions offer an adequate set of libraries and tools for high-quality prototyping of systems and for porting them to hardware platforms. Besides, the Matlab support of the.NETFramework platform and a set of external data, client, and server access interfaces enable unit and process models created earlier with the use of various programming languages to be integrated in the information support of the CETS.

Further research will be aimed at improving and detailing the models of the technological units of the CETS, as well as at increasing the quality of solutions and decisions resulting from the application of the artificial intelligence methods used in the information support of the control system architecture presented in this paper. For this purpose, a stack of technologies of self-refining digital twins is proposed for use, which provides adaptation of currently used CETS models to changing environmental conditions and requirements on process plant operation management.

\section{Conclusions}

It was found that the amounts of technogenic wastes from apatite-nepheline ore processing at mining-and-processing integrated works are large and cause significant environmental damage. It was stated that, in view of the rich chemical and mineralogical composition of such technogenic deposits, it is expedient to recycle them, and it is urgent to upgrade the information support of recycling plant control systems.

The architecture of an intelligent control system for a CETS of phosphorus production from apatite-nepheline ore waste was proposed, which supports the hierarchy of the information control model, from the level of controllers to the level of strategic production planning.

A concept of model-oriented design of a control system for the CETS of phosphorus production was presented, which provides an iterative process of error detection and elimination at different stages of creating the control system, as well as the highest compliance of the developed models and algorithms with the control aims.

A Matlab environment has been proposed for the implementation of the elements of the intelligent control system for the phosphorus production CETS. The application of the Matlab-developed program of intelligent tuning of a PID controller in the granulator control loop was given as an example. The application results showed that the intelligent tuning of the PID controller, which takes into account changes in the control object parameters, reduces the fluctuations of the output parameter of the granulator (at a constant control task) as compared to a controller having fixed tuning.

The presented architecture of the intelligent control system for the CETS can be improved and upgraded in view of new achievements in the field of machine learning and information technologies. It can also be adapted to other technological systems through the application of the concept of model-oriented design.

Author Contributions: Methodology, A.P. and A.V.; software, A.P., Y.S.; validation, A.P., A.V. and N.K.; formal analysis, A.P., M.D. and E.K.; investigation, N.K., Y.S.; writing-original draft preparation Y.S., N.K.; writing - review and editing, E.K.; visualization, E.K. and A.P.; project administration, M.D. All authors have read and agreed to the published version of the manuscript.

Funding: The research was performed within State Assignment No.FSWF-0019-2020 and financially supported by the RFBR, project No.18-29-24094 MK.

Institutional Review Board Statement: Not applicable.

Informed Consent Statement: Not applicable.

Data Availability Statement: Not applicable. 
Conflicts of Interest: The authors declare no conflict of interest. The funders had no role in the design of the study; in the collection, analyses, or interpretation of data; in the writing of the manuscript, or in the decision to publish the results.

\section{References}

1. Kharchenko, E.M.; Zhumashev, K.Z.; Selivanov, E.N. Development of Technology for Recycling Copper Smelting Production Waste. Metallurgist 2019, 62, 1250-1254. [CrossRef]

2. Gopalraj, S.K.; Kärki, T. A review on the recycling of waste carbon fibre/glass fibre-reinforced composites: Fibre recovery, properties and life-cycle analysis. SN Appl. Sci. 2020, 2, 433. [CrossRef]

3. Hilal, N.; Hadzima-Nyarko, M. Improvement of eco-efficient self-compacting concrete manufacture by recycling high quantity of waste materials. Environ. Sci. Pollut. Res. 2021. [CrossRef]

4. Koptsik, G.N.; Koptsik, S.V.; Smirnova, I.E.; Sinichkina, M.A. Remediation of Technogenic Barren Soils in the Kola Subarctic: Current State and Long-Term Dynamics. Eurasian Soil Sci. 2021, 54, 619-630. [CrossRef]

5. Meshalkin, V.P.; Dli, M.I.; Puchkov, A.Y.; Bobkov, V.I.; Kazak, A.S. Software for Efficient Chemical Technologies for Processing of Apatite-Nepheline Ore Waste. Dokl. Chem. 2021, 496, 42-47. [CrossRef]

6. Nibedita, B.; Irfan, M. The role of energy efficiency and energy diversity in reducing carbon emissions: Empirical evidence on the long-run trade-off or synergy in emerging economies. Environ. Sci. Pollut. Res. 2021. [CrossRef]

7. Schützenhofer, C. Overcoming the efficiency gap: Energy management as a means for overcoming barriers to energy efficiency, empirical support in the case of Austrian large firms. Energy Effic. 2021, 14, 45. [CrossRef]

8. Meshalkin, V.P.; Puchkov, A.Y.; Dli, M.I.; Bobkov, V.I. Generalized Model for Engineering and Controlling a Complex Multistage Chemical Energotechnological System for Processing Apatite-Nepheline Ore Wastes. Theor. Found. Chem. Eng. 2019, 53, 463-471. [CrossRef]

9. Liu, X.; Yuan, Z.; Liu, X.; Zhang, Y.; Hua, H.; Jiang, S. Historic Trends and Future Prospects of Waste Generation and Recycling in China's Phosphorus Cycle. Environ. Sci. Technol. 2020, 54, 5131-5139. [CrossRef]

10. Chen, X.; Nophut, C.; Voigt, T. A model-driven approach for engineering customizable MES with the application to the food and beverage industry. Int. J. Adv. Manuf. Technol. 2021, 115, 2607-2622. [CrossRef]

11. Qu, W.; Cao, W.; Su, Y.C. Design and implementation of smart manufacturing execution system in solar industry. J. Ambient. Intell. Hum. Comput. 2020. [CrossRef]

12. Holsapple, C.; Sena, M.; Wagner, W. The perceived success of ERP systems for decision support. Inf. Technol. Manag. 2019, 20, 1-7. [CrossRef]

13. Ren, M. Why technology adoption succeeds or fails: An exploration from the perspective of intra-organizational legitimacy. J. Chin. Sociol. 2019, 6, 21. [CrossRef]

14. Kultygin, O.P.; Lokhtina, I.V. Business intelligence as a decision support system tool. J. Appl. Inform. 2021, 16, 52-58. [CrossRef]

15. Stoianova, O.; Pasechnik, L. New applications of competency models in human resource management. J. Appl. Inform. 2019, 14, 18-28. [CrossRef]

16. Litvinenko, V.S. Digital Economy as a Factor in the Technological Development of the Mineral Sector. Nat. Resour. Res. 2020, 29, 1521-1541. [CrossRef]

17. Dli, M.; Puchkov, A.; Meshalkin, V.; Abdeev, I.; Saitov, R.; Abdeev, R. Energy and Resource Efficiency in Apatite-Nepheline Ore Waste Processing Using the Digital Twin Approach. Energies 2020, 13, 5829. [CrossRef]

18. Puchkov, A.; Dli, M.; Lobaneva, Y. Classification of the Technological Process Condition Based on Hybrid Neural Networks. In Cyber-Physical Systems: Modelling and Intelligent Control. Studies in Systems, Decision and Control; Springer: Cham, Switzerland, 2021; Volume 338. [CrossRef]

19. Long, B.; Li, X.; Gao, X.; Liu, Z. Prognostics Comparison of Lithium-Ion Battery Based on the Shallow and Deep Neural Networks Model. Energies 2019, 12, 3271. [CrossRef]

20. Ozden, T.; Kesler, S.; Okumus, H.I. A fuzzy logic embedded energy management software with multi-agent system for a stand-alone PV power plant. Int. J. Environ. Sci. Technol. 2019, 16, 5197-5204. [CrossRef]

21. Singh, K.V.; Bansal, H.O.; Singh, D. Feed-forward modeling and real-time implementation of an intelligent fuzzy logic-based energy management strategy in a series-parallel hybrid electric vehicle to improve fuel economy. Electr. Eng. 2020, 102, 967-987. [CrossRef]

22. Borase, R.P.; Maghade, D.K.; Sondkar, S.Y.; Pawar, S.N. A review of PID control, tuning methods and applications. Int. J. Dyn. Control 2021, 9, 818-827. [CrossRef]

23. Kumar, J.; Kumar, V.; Rana, K.P.S. Fractional-order self-tuned fuzzy PID controller for three-link robotic manipulator system. Neural Comput. Appl. 2020, 32, 7235-7257. [CrossRef]

24. Raj, F.V.A.; Kannan, V.K. Adaptive ELM neural computing framework with fuzzy PI controller for speed regulation in permanent magnet synchronous motors. Soft Comput. 2020, 24, 10963-10980. [CrossRef]

25. Boukhalfa, G.; Belkacem, S.; Chikhi, A.; Benaggoune, S. Genetic algorithm and particle swarm optimization tuned fuzzy PID controller on direct torque control of dual star induction motor. J. Cent. South Univ. 2019, 26, 1886-1896. [CrossRef]

26. Zhu, X.; Chen, K.; Wang, Y.; Zheng, H. Adaptive PID controller for cloud smart city system stability control based on chaotic neural network. Clust. Comput. 2019, 22, 13067-13075. [CrossRef] 
27. Lu, Y.; Yu, W.; Wang, J.; Jiang, D.; Li, R. Design of PID Controller Based on ELM and Its Implementation for Buck Converters. Int. J. Control Autom. Syst. 2021, 19, 2479-2490. [CrossRef]

28. Możaryn, J.; Petryszyn, J.; Ozana, S. PLC based fractional-order PID temperature control in pipeline: Design procedure and experimental evaluation. Meccanica 2021, 56, 855-871. [CrossRef]

29. Pinto, J.E.M.G.; Dantas, A.F.O.D.A.; Maitelli, A.; Dantas, A.D.O.D.S.; Dórea, C.E.T.; Campos, J.T.L.S.; Rego, E.J.D.C. PLC Implementation of Piecewise Affine PI Controller Applied to Industrial Systems with Constraints. J. Control Autom. Electr. Syst. 2019, 30, 311-322. [CrossRef]

30. Alikov, A.Y.; Kovaleva, M.A.; Rutkovskiy, A.L.; Tedeeva, N.V. Automation of optimal identification of dynamic element transfer functions in complex technical objects based on acceleration curves. Her. Dagestan State Tech. Univ. Tech. Sci. 2017, 44, 97-106. (In Russian) [CrossRef]

31. Lee, H.-J.; Jhang, S.-S.; Yu, W.-K.; Oh, J.-H. Artificial Neural Network Control of Battery Energy Storage System to Damp-Out Inter-Area Oscillations in Power Systems. Energies 2019, 12, 3372. [CrossRef]

32. Gil'fanov, K.K.; Shakirov, R.A. Neural Network Modeling of Thermal-Hydraulic Efficiency of Promising Surface Heat Transfer Intensifiers. Russ. Aeronaut. 2021, 64, 61-70. [CrossRef]

33. Eremenko, Y.I.; Poleshchenko, D.A.; Glushchenko, A.I. Rules for parameter adjustment in a PI controller for metallurgical heaters. Steel Transl. 2015, 45, 852-855. [CrossRef] 